\title{
El capital en la era de los monopolios generalizados: apuntes sobre el capital monopolista
}

\section{RAÚL DELGADO WISE*}

Transcurridos 150 años de la publicación del libro primero de El capital de Marx se constata su vigencia para desentrañar la naturaleza del capitalismo contemporáneo. Aun cuando los postulados de esa obra se refieren al «capital en general», es decir, al capital en el más alto nivel de abstracción, representa un imprescindible cimiento teórico-conceptual para penetrar en las contradicciones que caracterizan al capitalismo en su fase actual, la crisis civilizatoria. Como en ninguna otra época de su larga historia, uno de los rasgos más conspicuos de la sociedad burguesa, ahora en crisis, es la presencia avasalladora del capital monopolista. Con este artículo se pretende contribuir a la caracterización conceptual y al análisis de la metamorfosis del capital monopolista de la actual crisis del capitalismo.

\footnotetext{
* Director de la Unidad Académica de Estudios del Desarrollo, Universidad Autónoma de Zacatecas
}

A 150 años de la publicación de la primera edición en alemán del volumen primero de El capital de Karl Marx, resulta fundamental constatar su extraordinaria vigencia para desentrañar la naturaleza del capitalismo contemporáneo. Aun cuando los postulados planteados por Marx en esta trascendental obra se refieren al «capital en general», es decir, al capital en su más alto nivel de abstracción, constituyen un insoslayable cimiento teórico/conceptual para penetrar en las complejas, profundas y peligrosas contradicciones que caracterizan al capitalismo en su fase actual. Uno de los rasgos más conspicuos es la profusa presencia, como en ninguna otra época de la larga historia de la sociedad burguesa, del capital monopolista. A tal grado se ha erigido en el agente dominante de la econo- mía política internacional, que Samir Amin ${ }^{1}$ se refiere a esta etapa como la «era de los monopolios generalizados». Es preciso observar que mediante megafusiones y alianzas estratégicas, dicha fracción del capital ha alcanzado niveles de concentración y centralización hasta hace relativamente poco inimaginables:

Las mayores compañías del mundo (aquellas con más de \$1000 millones [de dólares estadounidenses] en ventas anuales)(...) dan cuenta de aproximadamente el 60 por ciento del ingreso, 65 por ciento de la capitalización de mercado y 75 por ciento de las ganancias [mundiales]. ${ }^{2}$

${ }^{1}$ Samir Amin, The implosion of capitalism, London, Pluto Press, 2013.

${ }^{2}$ McKinsey Global Institute, The world at work: jobs, pay, and skills for 3.5 billion People, McKinsey \& Co., 2012, p. 21, en http://www.mckinsey.com/insights/employment _and_growth/the_world_at_work/19/03/2015 
No se trata, empero, de un simple cambio cuantitativo, sino de una profunda transformación cualitativa en las formas de organización y dominio del capital monopolista basadas en la financiarización, las ventajas comparativas derivadas del arbitraje laboral global, dicho de otro modo, la persistencia de significativos diferenciales salariales entre países y regiones, ${ }^{3}$ sin ignorar las nuevas y brutales modalidades de saqueo de recursos naturales y devastación ambiental implantadas a lo largo y ancho del planeta.

El objetivo primordial es reflexionar acerca de una las figuras más emblemáticas y dominantes de nuestro tiempo: el capital monopolista. Interesa en principio contribuir a su caracterización conceptual a partir de una serie de postulados planteados por Marx en El capital, así como algunos textos relacionados con su obra cumbre, particularmente los Grundrisse. Posteriormente, con base en esta conceptualización - que ha sido objeto de una vasta y acalorada polémica en el marxismo contemporáneo - se pretende contribuir a dilucidar aspectos nodales de la metamorfosis experimentada por el capital monopolista en la actualidad y que se encuentran en la base de la crisis civilizatoria imperante.

\section{Para desentrañar la naturaleza del capital monopolista}

Marx no elaboró como tal una teoría del capital monopolista; sin embargo, en su análisis de la acumulación capitalista, como aspecto inmanente al desarrollo de la relación capital-trabajo asalariado, previó el desencadenamiento de una creciente tendencia hacia la concentración y centralización del capital, es decir, hacia la formación del capital monopolista. En esa pers-

${ }^{3}$ Raúl Delgado Wise y David Martin, «The political economy of global labour arbitrage», in Kees van der Pijl (ed.), The International Political Economy of Production, Cheltenham, Edward Elgar, 2015. pectiva, vislumbra un tipo de configuración monopólica, específica del modo capitalista de producción, que por ende rompe radicalmente con herencias de modos de producción anteriores, tal como lo plantea en el siguiente pasaje de los Grundrisse:

El señor Proudhon no habla más que del monopolio moderno engendrado por la competencia. Pero todos sabemos que la competencia ha sido engendrada por el monopolio feudal. Así pues, primitivamente la competencia ha sido lo contrario del monopolio, y no el monopolio lo contrario de la competencia. Por tanto, el monopolio moderno no es una simple antítesis, sino que, por el contrario, es la verdadera síntesis.

Tesis: El monopolio feudal anterior a la competencia.

Antítesis: La competencia.

Síntesis: El monopolio moderno, que es la negación del monopolio feudal por cuanto presupone el régimen de la competencia, y la negación de la competencia por cuanto es monopolio. ${ }^{4}$

Lo anterior significa que con el advenimiento del régimen capitalista de producción se inaugura una peculiar unidad contradictoria entre monopolio y competencia, donde el primero no implica la negación de la segunda y viceversa. Es crucial, en este sentido, observar que la construcción de la noción de monopolio en Marx se encuentra firmemente anclada en las relaciones sociales de producción y en las leyes tendenciales de la acumulación capitalista desarrolladas por él en el primer volumen de El capital. Ello implica que, a contracorriente de la concepción burguesa de monopolio, cuyo contenido parte de, y se circunscribe a, la esfera de la circulación, en el caso de la noción marxista, el punto de partida se ubica en la esfera de la producción de plusvalor y, por consiguiente,

\footnotetext{
${ }^{4}$ Karl Marx, Grundrisse: elementos fundamentales para la crítica de economía política, tomo 2, México, Siglo XXI, 1976 [1858], pp. 124-125.
} 


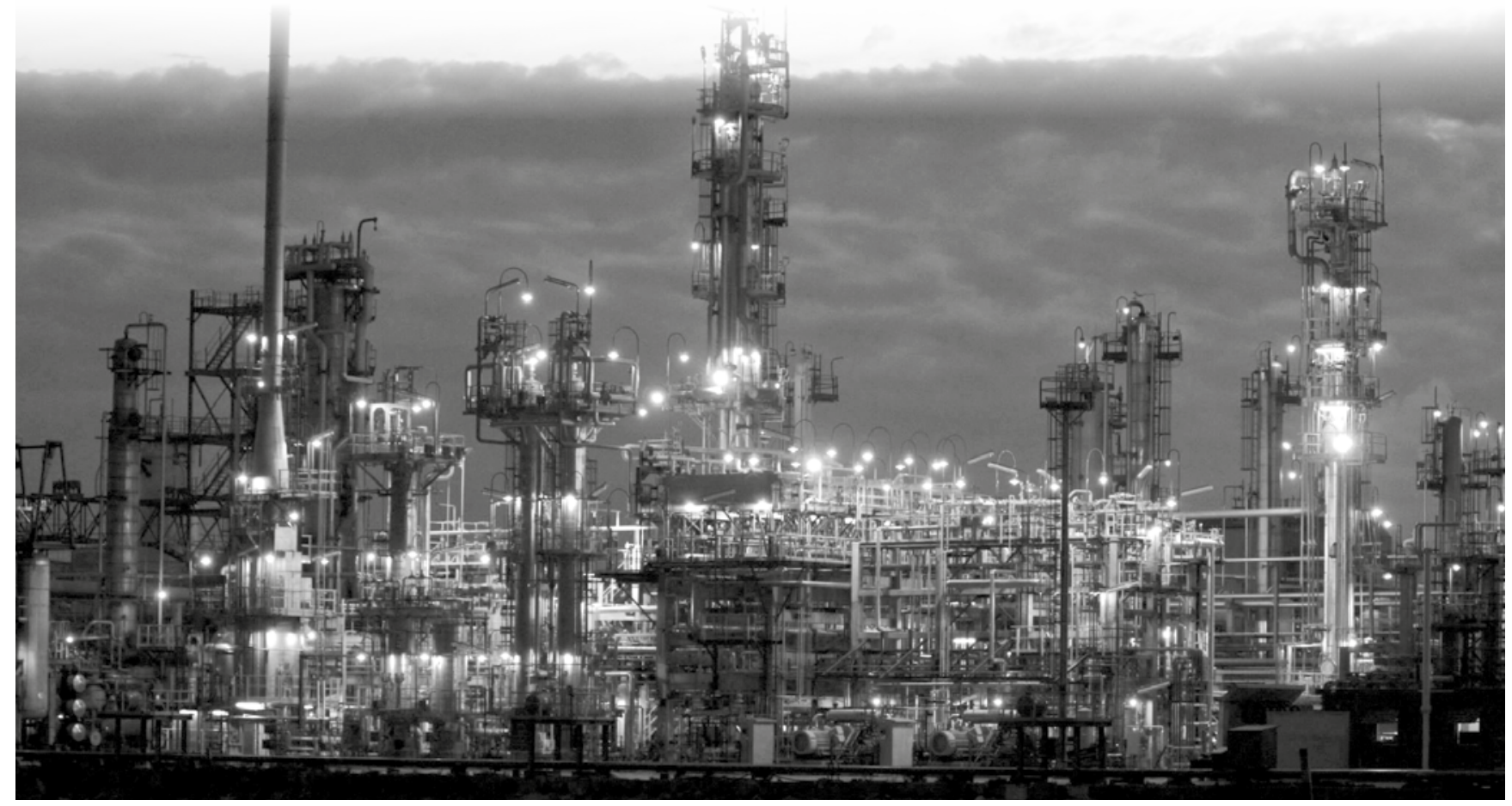

Incorporar el análisis del capital

monopolista

a la esfera

de la circulación posibilita establecer un puente analítico

con la esfera

de la distribución

del capital,

abordada por Marx. en la contradicción capital-trabajo asalariado. En otras palabras:

Aunque acumulación y competencia están íntimamente relacionadas, la primera puede concebirse y comprenderse antes que la segunda. Esto es así porque la acumulación es la expansión progresiva del circuito del capital, y éste se analiza en primer lugar para el capital en su conjunto, sin referirse a la interacción entre los diferentes capitales. Aquí debemos enfatizar que nos estamos refiriendo a la competencia entre capitales pues, ya que la base del capital es la separación del trabajo respecto de los medios de producción, el circuito del capital no puede abstraerse de la competencia entre capital y trabajo, es decir, de la propia lucha de clases. ${ }^{5}$

En contigua tesis, David Harvey plantea:

La idea que yo pretendo defender aquí (...) es que el poder de los monopolios es básico y no una aberración en el funcionamiento del capital, y que existe en unidad contradictoria con la competencia (...) ¿Cómo debemos entonces entender

${ }^{5}$ John Weeks, «Competencia y monopolio», Marxismo Crítico, 2011, p. 11, en https://marxismocritico.com/2011/11/04/ competencia-y-monopolio/ esa unidad contradictoria? El punto más obvio para empezar es afirmar que ambos aspectos son indistinguibles, o para ser más exactos, que ambos se fusionan dejando la contradicción en estado latente más que antagónico. Ese punto es la naturaleza de la propiedad privada que confiere a su dueño el monopolio sobre el uso de una mercancía. El poder monopolístico inherente a la propiedad privada constituye la base para el intercambio, y por extensión para la competencia. Esto puede parecer elemental, e incluso trivial, pero no lo es tanto cuando se reconoce que el poder de clase del capital descansa enteramente sobre el ensamblaje de todos esos derechos monopolísticos de propiedad individual en un orden social en el que la clase capitalista se puede definir frente al trabajo por su monopolio colectivo sobre los medios de producción (o en una versión más reciente, sobre los medios de financiación). Lo que está ausente en las acostumbradas discusiones sobre el monopolio es el concepto y la realidad del poder monopolístico de clase (el poder colectivo del capital), incluidas las rentas monopolísticas de clase, cuando se aplica a los procesos económicos y políticos. ${ }^{6}$

${ }^{6}$ David Harvey, Diecisiete contradicciones y el fin del capitalismo, Quito, Instituto de Altos Estudios Nacionales del Ecuador (IAEN), 2014, p. 139. 
La esfera de la circulación — desde donde la economía burguesa plantea su análisis del monopolio - es relevante, mas no determinante para la discusión del capital monopolista. En su análisis, a través del cual se devela la unidad contradictoria entre producción y realización (tomo II de El capital) Marx hace abstracción de la cuestión del capital monopolista. Es aquí donde Paul Baran y Paul Sweezy, en El capital monopolista, ${ }^{7}$ intentan completar su estudio agregando a los sectores I (bienes de producción) y II (bienes de consumo), un tercer sector en el que incorporan rubros crecientemente importantes para la reproducción y en concreto la realización del capital, como la propaganda asociada a las ventas, difusión y diferenciación de nuevas mercancías, así como los gastos militares y financieros. Más allá de la acuciosa polémica desencadenada por esta obra con relación a las categorías analíticas postuladas por Marx (véase al respecto, Paul Mattick), ${ }^{8}$ lo cierto es que la audacia de algunos de sus planteamientos — sin que los compartamos del todo - abren significativas vetas analíticas para el entendimiento del capitalismo contemporáneo. Las contribuciones de John Bellamy Foster ${ }^{9}$ y Samir Amin, ${ }^{10}$ tanto a la precisión conceptual como al desarrollo ulterior de los aportes de Baran y Sweezy, son fundamentales en esta última perspectiva.

Incorporar el análisis del capital monopolista a la esfera de la circulación posibilita establecer un puente analítico con la esfera de la distribución del capital, abordada por Marx. ${ }^{11}$ Es

${ }^{7}$ Paul Baran y Paul Sweezy, Monopoly capital: an essay on the american economic and social order, New York, Monthly Review Press, 1966.

${ }^{8}$ Paul Mattick, Crítica de la teoría económica contemporánea, México, Era, 1980.

9 John Bellamy Foster, The theory of monopoly capitalism: an elaboration of marxian political economy, New York, Monthly Review Press, 2014.

${ }^{10}$ Samir Amin, op. cit.

${ }^{11}$ Cabe destacar que los tomos II y III de El capital no son textos terminados y editados por Marx, son obras editadas y en algunos aspectos completadas por Friedrich Engels en 1885 y 1894, respectivamente. imprescindible considerar que en el tomo III se aborda la transformación de los valores en precios de producción, donde la competencia inter e intrasectorial desempeña un papel crucial en el proceso de formación de la tasa media de ganancia y de los precios. Referente a ello y con las dinámicas contradictorias de la acumulación de capital — expresadas en la ley tendencial a la caída de la tasa media de ganancia-, Marx examina temas vitales para la comprensión del capital monopolista: las ganancias extraordinarias derivadas de la productividad del trabajo (y el desarrollo capitalista de las fuerzas productivas), el interés y la renta del suelo.

No obstante, lo más importante es que en esta esfera se puede identificar aquello que figura como la razón de ser y el objetivo productivo básico del capital monopolista: la obtención de ganancias superiores a la media, esto es, ganancias extraordinarias o rentas monopólicas. ${ }^{12}$ De ahí que el precio de monopolio se defina — siguiendo a Marx - como un precio superior al precio de producción, un precio que se ubica por encima del costo de producción más la ganancia media y por tanto posibilita al capital monopolista apropiarse de una tajada relativamente mayor de la plusvalía social de aquella que le correspondería en condiciones de «competencia perfecta» (supuesto cardinal de la economía burguesa en su expresión neoclásica).

Cabe advertir que si bien el precio de monopolio implica una interferencia en el proceso de formación de los precios que permite transferencias de plusvalor de los trabajadores y capitalistas a los dueños de este tipo de capital, lo cierto es que en su acepción marxista no implica el establecimiento de un precio totalmente arbitrario, sino un precio que guarda relación con la ley del valor $\mathrm{y}$, por ende, con el principio de que la ganancia agregada no puede distanciarse

${ }^{12}$ Raúl Delgado Wise, «Progreso tecnológico y capital monopolista», Investigación Económica, núm. 216, 1996, pp. 85-101. 
banalmente de la masa agregada de plusvalor..$^{13}$ A la recurrente presencia de desajustes en este plano, en tanto desencadenantes de crisis periódicas, y a la necesidad de corregirlos o contrarrestarlos mediante la intervención estatal u otras vías es a lo que alude la ley tendencial de la caída de la tasa media de ganancia.

Otro rasgo básico del capital monopolista, en tanto condición sine qua non para la obtención de plusganancias, es la necesidad de mantener ventajas duraderas sobre otros posibles participantes en la rama o ramas particulares en las que opera. Tales ventajas pueden ser naturales o artificiales y a cada una de ellas corresponde una forma o combinación de formas de plusganancia, las que a su vez configuran formas particulares de organización monopólica. Una de estas formas guarda relación con el mecanismo previsto por Marx que hace revolucionario al capitalismo en cuanto al desarrollo de las fuerzas productivas: el cambio tecnológico. Al respecto, Joseph A. Shumpeter ${ }^{14}$ — sin pretender, ni mucho menos, identificar su visión del cambio tecnológico con la planteada por Marx en El capital - propone la existencia de una relación positiva entre innovación y poder monopólico, al postular que la competencia mediante la primera es el medio más eficaz para adquirir ventajas sobre posibles competidores. El propio Schumpeter llega a sostener que la innovación es tanto un medio para alcanzar ganancias monopólicas, como un método para mantenerlas. Ello implica, a contra sensu de lo que postulan — aun sea en términos relativos - algunos teóricos contemporáneos del capital monopolista como Baran y Sweezy ${ }^{15}$ y Ernest Mandel, ${ }^{16}$ que

\footnotetext{
${ }^{13}$ Alfred Evenitsky, «Monopoly capitalism and Marx's economic doctrines», Science \& Society, vol. 24, núm. 2, 1960, pp. 134-149.

${ }^{14}$ Joseph Shumpeter, Business cycles: a theoretical, historical and statistical analysis of the capitalist process, London, McGraw-Hill, 1939; Joseph Shumpeter, Capitalism, socialism and democracy, New York, Harper \& Brothers, 1942.

${ }^{15}$ Paul Baran y Paul Sweezy, op. cit.

${ }^{16}$ Ernest Mandel, El capitalismo tardío, México, Era, 1980.
}

el capital monopolista más que una barrera o freno al cambio tecnológico, tiende a acelerarlo en su insaciable apetito de plusganancias.

Cabe acotar, sin embargo, que en la concepción marxista del cambio tecnológico no hay una identificación mecánica o directa de esta última con una visión positiva del progreso. Por el contrario, al estar regido por la ley del valor-trabajo, el cambio tecnológico tiende a apartarse de la lógica del valor de uso. En concreto, el capital monopolista, como agente acelerador de la innovación y el cambio tecnológico, no escapa a las contradicciones que entraña la modernidad capitalista y que deviene en un tipo de modernidad que, como lo subraya Bolívar Echeverría: ${ }^{17}$

Conduce ella misma, estructuralmente, por el modo como se organiza el proceso de reproducción de la riqueza social (...) a la destrucción del sujeto social y a la destrucción de la naturaleza dentro de la cual este sujeto social se afirma a sí mismo.

Pero el capital monopolista no sólo se nutre de ganancias extraordinarias asociadas a la innovación y el cambio tecnológico, sino que a la par o en conjunción con ellas, se alimenta de otras formas de plusganancia o rentas monopólicas analizadas por Marx en el tomo III de El capital, como es el caso del interés y la renta del suelo. Unas y otras interfieren en el proceso de formación de los precios y la distribución del plusvalor: a) Acelerando en mayor o menor grado la productividad del trabajo y profundizando con ello la tendencia a la caída de la tasa de ganancia. b) Sustrayendo crecientes porciones de plusvalor de los trabajadores u otros capitalistas. c) Agudizando, en niveles históricos, las dinámicas de desarrollo desigual y la transferencia de excedentes entre

${ }^{17}$ Bolívar Echeverría, Antología. Crítica de la modernidad capitalista, La Paz, Oxfam/Vicepresidencia del Estado Plurinacional de Bolivia, 2011; Guillermo Foladori, Estudios Críticos del Desarrollo, vol. 4, núm. 7, 2014, p. 173. 
diferentes demarcaciones político-territoriales como medidas contratendenciales frente a los crecientes problemas de realización. d) Distorsionando los mecanismos que posibilitan el crecimiento económico y la reproducción ampliada de capital. e) Exacerbando, a grados extremos e incluso peligrosos, las contradicciones del sistema y la profundidad de sus crisis.

Por su propia naturaleza, el ámbito en el que se desenvuelve el capital monopolista es el correspondiente a la acumulación de capital a escala mundial. Aunque se trata de un ámbito analítico que no fue abordado en $\mathrm{El}$ capital, se trata de una asignatura pendiente prevista por el propio Marx en los diversos planes para el desarrollo de su obra esbozados en los Grundrisse. ${ }^{18}$ Esta tarea, vital para la comprensión del contenido y las metamorfosis emprendidas por el capital monopolista, ha sido retomada y profusamente acometida en el marxismo contemporáneo a través, entre otros, de los aportes de Rudolf Hilferding, Paul Sweezy, Paul Baran, Paul

${ }^{18}$ Roman Rosdolsky, Génesis y estructura de El capital de Marx (estudios sobre los Grundrisse), México, Siglo XXI, 1978.
Mattick, Harry Magdoff, Ernest Mandel, Harry Braverman, John Bellamy Foster y Samir Amin. Lo significativo de las contribuciones de estos y otros autores es que vinculan la cuestión del capital monopolista con la evolución del imperialismo y las dinámicas de desarrollo desigual que lo acompañan. Asimismo, son significativos los aportes de los teóricos de la dependencia: Theotonio Dos Santos y Ruy Mauro Marini.

\section{Metamorfosis del capital monopolista bajo la égida neoliberal}

Según se indicó al principio, el capital monopolista figura hoy como el agente dominante de la economía política internacional. A su abrumadora supremacía en términos de acervos de capital fijo, ingresos, ventas y ganancias sobre otras fracciones del capital, se agrega el advenimiento de profundas transformaciones cualitativas en sus formas de organización y dominio planetario, entre las que sobresale:

a) Recurso a la financiarización, referida al ascenso y prerrogativa del capi-

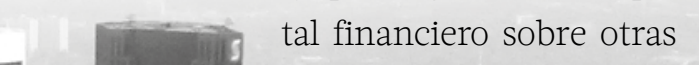

El capital monopolista más que una barrera o freno al cambio tecnológico, tiende a acerlerarlo en su insaciable apetito de plusganancias. 
fracciones del capital monopolista. ${ }^{19}$ Ante la falta de inversiones redituables en la esfera productiva por la crisis de sobreproducción desencadenada a fines de la década de 1970, el capital inicia un fuerte viraje hacia la especulación financiera posibilitado por las nuevas Tecnologías de la Información y la Comunicación (TIC)..$^{20}$ De igual modo, con la presión a la baja que se ejerce sobre los salarios reales mediante el arbitraje laboral global, se desencadena una explosión de deudas encabezada por el sector financiero, la cual permite que la producción encuentre canales, aun sean endebles e insustentables, de «realización». Se produce así una financiarización de la clase capitalista, del capital industrial y de las ganancias corporativas, ello da lugar a una explosión de capital ficticio, es decir, de títulos financieros sin contraparte en la producción material. ${ }^{21} \mathrm{Se}$ trata claramente, como lo subraya Sergio Rodríguez Lascano, ${ }^{22}$ de una mutación del ciclo básico del capital D-M-D’ en D-D'.

b) La configuración de redes globales de capital monopolista generadas a partir de una estrategia de reestructuración liderada por las grandes corporaciones multinacionales que, mediante operaciones de outsourcing y cadenas de subcontratación, extienden partes de sus procesos productivos, comerciales, financieros y de servicios a los países periféricos en busca de mano de obra flexible y barata. Un claro ejemplo de esa estrategia son las plataformas de exportación que ope-

${ }^{19}$ Walden Bello, Dilemmas of domination: the unmaking of the american empire, Nueva York: Metropolitan Books, 2005. ${ }^{20}$ Robert Brenner, The boom and the bubble: the U.S. in the world economy, New York, Verso, 2002.

${ }^{21}$ John Bellamy Foster, «The financialization of the capitalist class: monopoly finance capital and the new contradictory relations of ruling class power», en Henry Veltmeyer (ed.), Imperialism, crisis and class struggle: the enduring verities and contemporary face of capitalism, Leiden/Boston, Brill Publishers, 2010.

${ }^{22}$ Sergio Rodríguez Lascano, «Apuntes sobre el pensamiento crítico versus las mutaciones de la hidra», en El pensamiento crítico frente a la hidra capitalista II, México, EZLN, 2015, pp. 434-455. ran como economías de enclave en los países periféricos.

Este giro hacia lo que algunos autores como Gary Gereffi y Timothy Sturgeon ${ }^{23}$ caracterizan como cadenas globales de valor ha sido espectacular:

Las 100 mayores corporaciones globales han desplazado su producción hacia sus filiales extranjeras [principalmente en el Sur], donde ahora se localizan cerca de 60 por ciento del total de sus bienes y empleados y más de 60 por ciento de sus ventas a nivel global. ${ }^{24}$

Se trata, en el fondo, de un «nuevo <nomadismo> surgido al interior del sistema de producción global, en el que la selección de localidades se determina en buena parte a partir de dónde es más barata la mano de obra». ${ }^{25}$ En esta perspectiva, cabe destacar lo siguiente: 1 ) $\mathrm{Al}$ menos 40 por ciento del comercio mundial se asocia a operaciones de outsourcing, incluyendo subcontrataciones y comercio intrafirma entre filiales de una misma compañía. ${ }^{26}$ 2) Se estima que en la periferia capitalista hay 85 millones de trabajadores directamente empleados en más de 3 mil 500 zonas de procesamiento para la exportación ubicadas en 130 países. ${ }^{27}$

La estrategia de reestructuración en cuestión ha modificado la geografía global de la producción a grado tal que actualmente poco más de 70

${ }^{23}$ Gary Gereffi y Timothy Sturgeon, «Global value chainoriented industrial policy: the role of emerging economies», en Deborah K. Elms y Patrick Low (eds.), Global value chains in a changing world, Geneva, World Trade Organization, 2013, pp. 329-360.

${ }^{24}$ United Nations Conference on Trade and Liberalization (UNCTAD), World Investment Report 2010, Nueva York, UNCTAD, 2010.

${ }^{25}$ John Bellamy Foster, Robert W. McChesney y Jamil Jonna, «The internationalization of monopoly capital», Monthly Review, vol. 63, núm. 2, 2011a, p. 18.

${ }^{26}$ Wladimir Andreff, «Outsourcing in the new strategy of multinational companies: foreign investment, international subcontracting and production relocation», Papeles de Europa, núm. 18, 2009, pp. 534.

${ }^{27}$ McKinsey Global Institute, op. cit. 
por ciento del empleo industrial se localiza en países periféricos. ${ }^{28}$ Lo sobresaliente de esta estrategia es que descansa en el aprovechamiento y profundización de las brechas salariales entre países y regiones, es decir, el arbitraje laboral global que para algunos autores como Intan Suwandi y John Bellamy Foster ${ }^{29}$ constituye el sello distintivo del imperialismo contemporáneo. Bajo este nuevo andamiaje, las grandes corporaciones multinacionales logran obtener ganancias extraordinarias mediante el establecimiento de límites a la libre movilidad de la más importante mercancía para la acumulación de capital: la fuerza de trabajo. ${ }^{30}$ Con ello se interfiere el proceso de formación de los precios de producción a

${ }^{28}$ John Bellamy Foster, Robert W. McChesney y Jamil Jonna, «The global reserve army of labour and the new imperialism», Monthly Review, vol. 63, núm. 6, 2011b, p. 115.

${ }^{29}$ Intan Suwandi y John Bellamy Foster, «Multinational corporations and the globalization of monopoly capital. From the 1960's to the present», Monthly Review, vol. 68, núm. 3, 2016.

${ }^{30}$ Raúl Delgado Wise y David Martin op. cit. favor de una vasta transferencia de plusvalor en dirección periferia-centro, sustentada en las posibilidades de reestructuración productiva que abren las TIC, pero que nada tiene que ver con el avance hacia una ruta progresista de desarrollo de las fuerzas productivas.

c) El extractivismo y el nuevo extractivismo, ${ }^{31}$ en alusión a la creciente apropiación y exportación de minerales, petróleo y gas de los países periféricos por las grandes corporaciones extractivas nacionales y multinacionales, a través de la sobreexplotación de recursos naturales y la consecuente expropiación de bienes comunes para la obtención de jugosas plusganancias bajo la forma de renta del suelo, sea en su modalidad absoluta o diferencial (incluyendo sus variantes I y II). Este fenómeno se asocia también a la presencia de procesos de financiarización y acumulación por

${ }^{31}$ Eduardo Gudynas, Extractivismos. Ecología, economía y política de un modo de entender el desarrollo y la Naturaleza, Bolivia, Centro de Documentación e Información Bolivia (CEDIB), 2015.
El caso del interés y la renta del suelo: unas y otras interfieren en el proceso de formación de los precios y la distribución del plusvalor agudizando, a niveles históricos, las dinámicas de desarrollo desigual.

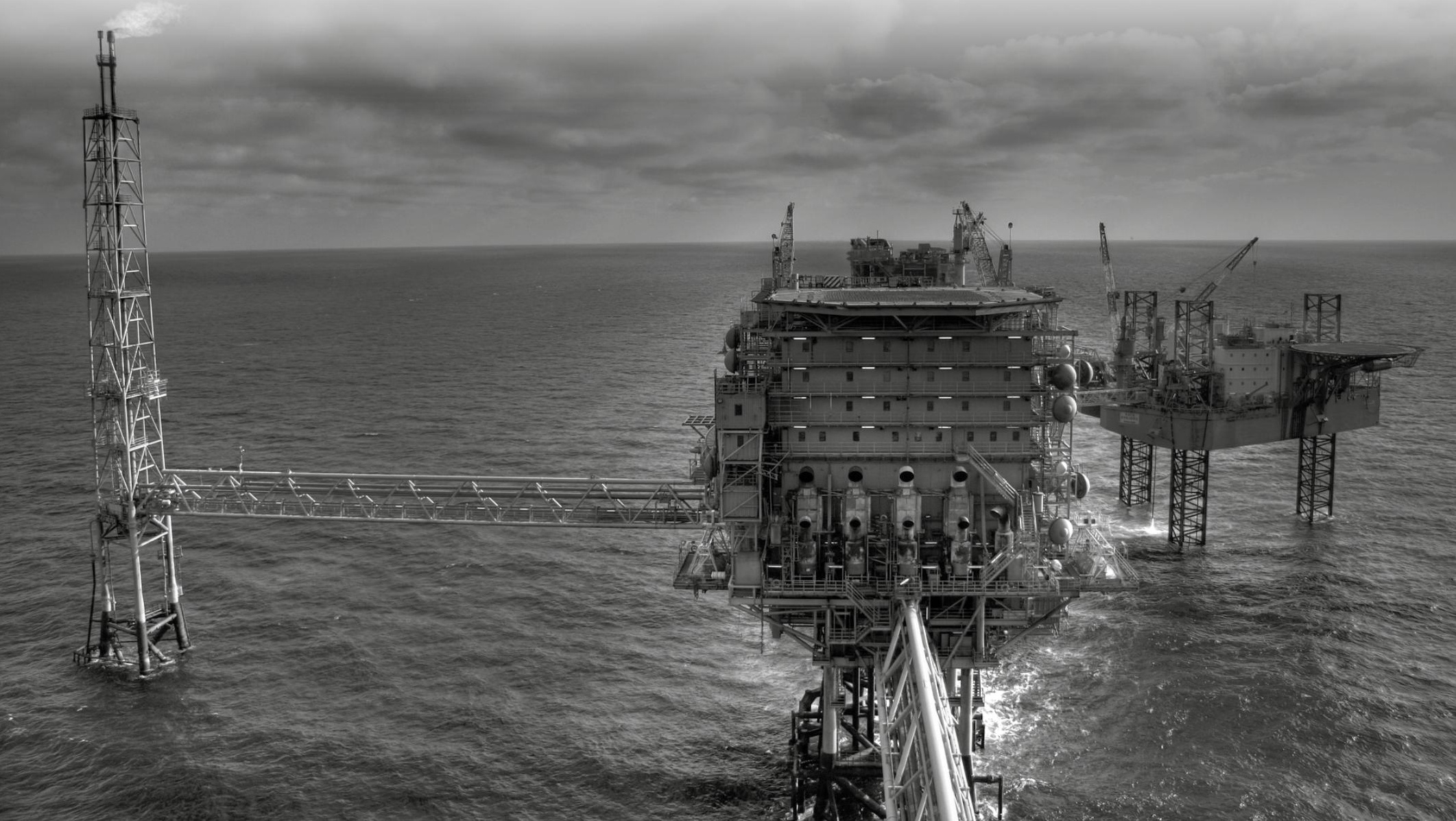


desposesión, que han traído consigo la exacerbación de conflictos sobre territorios y aguas, ${ }^{32}$ así como afectaciones cada vez más severas al medio ambiente a través de la minería a tajo o cielo abierto, el fracking, el gas lutitas, etcétera.

Dado que los ingresos de algunas de las corporaciones multinacionales más poderosas del mundo dependen de la extracción, producción y consumo de combustibles fósiles, lo más probable es que este patrón persista, ahondando aún más la crisis ecológica y sus efectos sobre el calentamiento global y el cambio climático. La nueva ola extractivista desencadenada por la reestructuración neoliberal ha empeorado la degradación ambiental, no sólo al expandir la geografía de la destrucción, también mediante la estrategia del arbitraje ambiental regulatorio por parte del capital extractivista. ${ }^{33}$

d) El acaparamiento o control de la tierra y recursos naturales por los agronegocios (land grabbing). Este fenómeno se asocia a cambios en los regímenes alimentarios acompañados de dinámicas de financiarización, procesos de acumulación por desposesión (que han implicado un brutal despojo de campesinos y pueblos originarios), cambios en los patrones de cultivo (monocultivo, uso de transgénicos, entre otros) y daños severos e irreversibles al entorno natural (pérdida de biodiversidad, destrucción de suelos, quebranto de la soberanía alimentaria). ${ }^{34}$ Así, se produce de igual modo una significativa expropiación de bienes comunes y apropiación de rentas monopólicas, con la consecuente exacerbación de los conflictos so-

\footnotetext{
${ }^{32}$ Henry Veltmeyer, «The political economy of natural resource extraction: a new model or extractive imperialism?», Canadian Journal of Development Studies, vol. 34, núm. 1, 2013, pp. 79-95.

${ }^{33}$ Yuquing Xing y Kolstad Charles, «Do lax environmental regulations attract foreign investment?», Environmental and Resource Economics, vol. 21, núm. 1, 2002, pp. 1-22.

${ }^{34}$ Saturnino M. Jr. Borras, Jennifer C. Franco, Sergio Gómez, Cristóbal Kay y Max Spoor, «Land grabbing in Latin America and the Caribbean», The Journal of Peasant Studies, vol. 39, núms. 3-4, 2012, pp. 845-872.
}

bre territorios y aguas. En el trasfondo de dicha compleja e intrincada trama subyace una quinta dimensión de la metamorfosis experimentada por el capital monopolista.

e) La profunda reestructuración acometida por los sistemas de innovación a partir de la década de 1990, la cual es básica para comprender aspectos nodales de las contradicciones que caracterizan al capitalismo contemporáneo y se encuentran en la base de la etapa actual de dominación imperialista. Semejante reestructuración cuyo epicentro es Silicon Valley, ha posibilitado al capital monopolista poner a su servicio las capacidades humanas para producir conocimiento - o el general intellect utilizando el concepto acuñado por Marx - del centro y la periferia, hecho que reduce costos laborales, transfiere riesgos y responsabilidades y capitaliza los beneficios mediante la apropiación y concentración de patentes..$^{35}$

Lo anterior ha provocado la configuración de lo que podría concebirse como un sistema imperial de innovación caracterizado por diversos aspectos: a) Creciente internacionalización y fragmentación de las actividades de innovación. ${ }^{36}$ b) Creación de ciudades científicas, como Silicon Valley en Estados Unidos y sus satélites en países periféricos o emergentes, que operan como una suerte de maquiladoras científicas. ${ }^{37}$ c) Desarrollo de nuevos métodos para

\footnotetext{
${ }^{35}$ Raúl Delgado Wise, op. cit.; Raúl Delgado Wise y Mónica Chávez Elorza, «Patentad, patentad: apuntes sobre la apropiación del trabajo científico por las grandes corporaciones multinacionales», Observatorio del Desarrollo, vol. 4, núm. 15, 2016; Pablo Míguez, «Del General Intellect a las tesis del <capitalismo cognitivo>: aportes para el estudio del capitalismo del siglo XXI», Bajo el Volcán, vol. 13, núm. 21, 2013, pp. 27-57.

${ }^{36}$ Henry Chesbrough, «Open innovation: a new paradigm for understanding industrial innovation», en Henry Chesbrough, Wim Vanhaverbeke y Joel West (eds.), Open innovation: researching a new paradigm, Oxford, Oxford University Press, 2008.

${ }^{37}$ AnnaLee Saxenian, Local and global networks of immigrant professionals in Silicon Valley, San Francisco, Public Policy Institute of California, 2002; AnnaLee Saxenian, The
} 
controlar agendas de investigación por las grandes corporaciones multinacionales con base en capital de riesgo, asociaciones empresariales y subcontrataciones en el ámbito de empresas emergentes o startups. d) Creciente participación de fuerza laboral altamente calificada proveniente de países periféricos o emergentes en las dinámicas de innovación en Silicon Valley y en sus apéndices periféricos. ${ }^{38}$ e) Creación de un marco institucional ad hoc para la concentración y apropiación de los productos generados por el trabajo científico a través de patentes, conformado por la Organización Mundial de la Propiedad Intelectual (OMPI) y la Organización Mundial de Comercio (OMC). ${ }^{39}$

Todo esto ha desencadenado una apropiación sin precedentes del conocimiento, en tanto bien común intangible, lo que ha propiciado, en principio, una desbordante expansión y privatización de los productos del general intellect, expresada en un crecimiento exponencial de las patentes acompañado de una concentración de ellas en un puñado de grandes corporaciones multinacionales, según lo constatan las estadísticas de la OMPI. Posteriormente, esa reestructuración arrastra consigo las contradicciones que encierra la modernidad capitalista en virtud de que, más allá de favorecer una ruta progresista de desarrollo de las fuerzas productivas, inaugura, como se ha consignado, una fase regresiva y oscurantista en el avance y aplicación del conocimiento.

\section{Epílogo: el capital monopolista en el espejo de la crisis civilizatoria}

La otra vertiente de la profunda reestructuración y la espectacular concentración y centralización del capital en manos del capi-

new argonauts: regional advantage in a global economy, Boston, Harvard University Press, 2006.

${ }^{38}$ Battelle, «Global R\&D funding forecast», Battelle-R\&D, 2014, en http://www.battelle.org/docs/tpp/2014_global_rd_ funding_forecast.pdf

${ }^{39}$ Raúl Delgado Wise y Mónica Chávez, op. cit. tal monopolista en mancuerna con el Estado imperial es la brutal embestida desencadenada en contra de la clase trabajadora y los sectores populares en prácticamente todos los rincones del planeta. Así, una pieza más del imperialismo contemporáneo es una reconfiguración de la división internacional del trabajo, donde la fuerza de trabajo pasa a figurar de manera abierta, a tono con la perspectiva marxista planteada por Arghiri Emmanuel ${ }^{40}$ para analizar el intercambio desigual, como la principal mercancía de intercambio entre países centrales y periféricos, lo cual ha dado lugar a la aparición de nuevas y extremas formas de intercambio desigual. ${ }^{41}$ La dinámica de creciente internacionalización de las finanzas, la producción, el comercio y los servicios propios del capitalismo neoliberal, ha tenido como correlato una creciente fragmentación y polarización de la geografía mundial acompañada de un desbordante crecimiento de las desigualdades sociales a niveles hasta hace poco inimaginables:

Tan sólo 8 personas (8 hombres en realidad) poseen ya la misma riqueza que 3.600 millones de personas, la mitad más pobre de la humanidad. La súper concentración de riqueza sigue imparable. El crecimiento económico tan sólo está beneficiando a los que más tienen. El resto, la gran mayoría de ciudadanos de todo el mundo y especialmente los sectores más pobres, se están quedando al margen de la reactivación de la economía. El modelo económico y los principios que rigen su funcionamiento nos han llevado a esta situación que se ha vuelto extrema, insostenible e injusta. Es hora de plantear una alternativa. ${ }^{42}$

\footnotetext{
${ }^{40}$ Emmanuel Arghiri, El intercambio desigual: ensayo sobre los antagonismos en las relaciones económicas internacionales, México, Siglo XXI, 1972.

${ }^{41}$ Humberto Márquez y Raúl Delgado Wise, «Signos vitales del capitalismo neoliberal: imperialismo, crisis y transformación social», en Estudios Críticos del Desarrollo, vol. 1, núm. 1, 2011, pp. 11-50.

${ }^{42}$ Informe de OXFAM, 2017, p. 1.
} 
Este «orden» o desorden planetario encierra profundas y peligrosas contradicciones ${ }^{43}$ que desde la década de 1970 han sumergido al capitalismo mundial en una profunda crisis que abrió la puerta a la implantación del neoliberalismo y que persiste hasta nuestros días. En efecto, la Hidra capitalista con sus nuevos rostros - en alusión a la extraordinaria metáfora del movimiento zapatista para referirse al régimen del capital — sólo ha encontrado falsas y limitadas salidas a la crisis que le dio origen y peor aún, lejos de abrir caminos hacia una fase sostenida de crecimiento de la economía mundial, a cada paso ha contribuido a repensar dicha crisis y desatar la tormenta. En opinión de Humberto Márquez:

internacionalización de las finanzas, la producción, el comercio y los servicios propios del capitalismo neoliberal, ha tenido como correlato un desbordante crecimiento de las desigualdades sociales a niveles hasta hace poco inimaginables.

\section{${ }^{43}$ David Harvey, op cit.}

La crisis que afronta el capitalismo contemporepresenta una ruptura en el proceso de expansión capitalista promovido por los pais de la década de los setenta. Se trata de una reestructuración fallida que ha hecho colapsar al centro mismo del sistema capitalista mundial, sobre todo a sus centros financieros e industriales más dinámicos, y que se ha transmitido con prontitud hacia todos los sectores, circuitos y rincones del capitalismo. Sin embargo, no podemos perder de vista que la estrategia de reestructuración y expansión ha cumplido con creces su cometido principal: concentrar capital, poder y riqueza en manos de una delgada elite de capitalistas transnacionalizados y, en contrapartida, ha deteriorado de manera drástica las condiciones de vida y trabajo de la mayoría de la población. ${ }^{44}$

Asistimos, por consiguiente, a una profunda crisis multidimensional: financiera, económica, social, cultural y ecológica, que no únicamente ha puesto en jaque al sistema capitalista, sino que al cuestionar las bases materiales de la vida, el trabajo y la naturaleza, ha adquirido dimensiones civilizatorias. Y es justo en el espejo de esta crisis donde se refleja, sin ambages, el curso seguido por el capital monopolista.

${ }^{44}$ Humberto Márquez, «La gran crisis del capitalismo neoliberal», Andamios, núm. 13, 2010, p. 67. 